\title{
Half a Global Problem or Guidelines for the Future ?
}

Earth from space is "a small and fragile ball dominated not by human activity and edifice but by a pattern of clouds, oceans, greenery and soils. Humanity's inability to fit its doings into that pattern is changing planetary systems, fundamentally. Many such changes are accompanied by life-threatening hazards. This reality, from which there is no escape, must be recognized - and managed." Thus begins Our Common Future, the final report of the World Commission on Environment and Development set up by the United Nations. After nearly three years of deliberations and public hearings around the world, the Commission released its analysis and recommendations last May amidst a great fanfare from the media. Reviews since have rated the WCED report variously as "a remarkable achievement" or "wishful thinking."

The report is based on the concept of "sustainable development .... that meets the needs of the present without compromising the ability of future generations to meet their own needs." To achieve this it is necessary to recognize and deal with the limitations ("interlocking crises") imposed on growth by the state of technology and social organization. The Commission calls for consumption standards that are within the bounds of the ecologically possible, and attention is focussed on population and human resources, food security, the loss of species and genetic resources, the need for a "safe and sustainable energy pathway," and the improvement of "strategies to guide the process of urbanization."

The report is full of ringing statements such as "Nations must turn away from the destructive logic of an arms culture and focus instead on their common future." "National boundaries have become so porous that traditional distinctions between local, national and international issues have become blurred." Concerning the institutional separation between those responsible for managing natural resources and protecting the environment and those in charge of managing the economy, "the real world of interlocked economic and ecological systems will not change; the policies and institutions concerned must." Few would find great fault with these declarations.

The report makes many recommendations, addressed mainly to governments, for institutional and legal change. For example, it proposes the setting-up of a Global Risks Assessment Program to identify critical environmental threats, to assess their causes and consequences, and to provide advice on what should be done about them. $\mathrm{Na}$ tional, regional and inter-regional agencies such as the World Bank are urged to take more responsibility for ensuring that their programs support development that is both economically and ecologically sustainable. The main call for action, however, is brief and is addressed to the United Nations General Assembly, urging it to "transform" the WCED report into a UN Program on Sustainable Development. This is a rather weak conclusion to a powerful synthesis of global problems, however incomplete.

The report takes into account the perspectives of environmental groups, economists, social scientists, public leaders and ordinary citizens; almost every point of view is represented except that of the physical and earth scientists. Perhaps this is not surprising, since few of us appear to have taken the time to make our views known. Indeed, one of the very few submissions - if not the only one - by earth scientists to the Commission was made by the late W.W. Hutchison, on behalf of IUGS (see Episodes, June 1986). He argued that in drawing up a new agenda for environment and development it would be necessary to take into account not only sectoral, economic and trade policies, but also natural processes that operate regardless of human activities.

Dr. Hutchison pointed out that sea-level change, climatic variations, land subsidence, floods, earthquakes, and volcanoes, for example, have all had profound effects on society at one time or another. To understand and cope with these events would require baseline studies to determine "background values," analysis and reconstruction of natural variations of the past, and development of a capability to forecast and predict the forces of nature. Likewise, the complex issues surrounding the disposal of hazardous (and nuclear) wastes would require continued scientific research. The text of Our Common Future bears little evidence that this message was heard, understood, or regarded as significant.

What an opportunity lost to stress the urgency for a thorough study of all the forces of environmental change, natural as well as man-made. What a chance missed to gain public support for the Global Change program or for an international effort on reducing natural hazards. Did the WCED have "tunnel vision", or did we simply fail to put our views strongly enough and in terms readily understandable by the many intelligent and experienced people who made up or influenced the Commission?

For that matter, it is always chastening to be reminded how little effect the earth sciences appear to have had on the programs of international agencies like the UN. This can hardly be because of the lack of strong statements of the need for more research and follow-up on this socially relevant problem or that one, from the forecasting of natural hazards, to the strengthening of scientific communities in the Third World, from the assessment of petroleum resources and the development of better mineral deposit models, to the development of the small mining sector. Yet look at the annual budget of ICSU, IUGS, AGID, CPCEMR and CCOP and imagine what could be accomplished with financial inputs of a few million dollars, the sort of amounts that are frittered away daily by wasteful governments or even that fuel a modest mineral exploration program covering a dozen square kilometres of ground.

Is our message trite, or are we simply failing to state it clearly? Could it be that our greatest challenge is the very unglamorous one of learning how to communicate effectively and forcefully with the planners, politicians and policy-makers?

\section{$\begin{array}{lllllllllllll}I N & T H & E & N & E & X & T & I & S & S & U & E\end{array}$}

GEOLOGY OF THE U.S.A.

An overview of current ideas on its geological evolution, mineral resources and geoscience institutes.

To mark the forthcoming 28 th

International Geological Congress to be held in Washington, D.C., in August 1989. 